\title{
$21^{\circ}$ COLE - ARTIGOS
}

\section{IMAGENS DE MENINA: LIVROS DE LITERATURA INFANTOJUVENIL DE TRÊS ESCRITORAS}

\author{
Priscila Kaufmann Corrêa ${ }^{1}$
}

Este trabalho apresenta imagens de meninas, selecionadas de livros de literatura infantojuvenil de três escritoras do século XIX e XX: a Condessa de Ségur (França), Louisa May Alcott (EUA) e Maria Clarice Marinho Villac (Brasil). A partir de cada livro, foram criadas ilustrações, que trazem a representação de meninas da elite em cada um dos três países. No caso dos livros da Condessa de Ségur são crianças da aristocracia francesa, nos de Louisa May Alcott são meninas da burguesia norte-americana e nos de Maria Clarice Marinho Villac são crianças da aristocracia patriarcal brasileira.

Cada uma das escritoras produziu diferentes livros, trazendo à tona as histórias de meninas e jovens, que são peraltas e rebeldes. Em cada momento os adultos estão presentes, indicando e orientando para que as crianças e jovens sigam pelo caminho tido como reto, adequado nos padrões destas elites.

Para o presente estudo foram selecionados os livros "Les vacances" (1859), da Condessa de Ségur, "Little women"3 (1868), de Louisa May Alcott e "Clarita no colégio" (1945), de Maria Clarice Marinho Villac. As primeiras edições de seus livros foram ricamente ilustradas, trazendo as imagens de meninas e jovens em diferentes situações. Essas ilustrações trazem uma representação de como são essas crianças e jovens, especialmente do sexo feminino. Segundo Chartier (2002, p. 17):

As representações do mundo social assim construídas, embora aspirem à universalidade de um diagnóstico fundado na razão, são sempre determinadas pelos interesses de grupo que as forjam. Daí, para cada caso, o necessário relacionamento dos discursos proferidos com a posição de quem as utiliza.

Neste sentido, a representação visa atuar sobre a subjetividade do indivíduo para que ele aceite, de maneira autoritária, a organização social e seus projetos, sejam eles políticos, sociais ou educacionais. Tais representações são construídas por um grupo que auxilia na constituição de sua identidade social e, ao mesmo tempo, as apresenta e difunde entre outros grupos, que podem se identificar, resistir ou rejeitar tais representações.

As representações são símbolos e as imagens, seja pela ilustração, seja pela narrativa, trazendo as vivências destas personagens da elite e o que é esperado da educação de meninas e jovens. Ao atentar para as ilustrações, nota-se as expectativas em torno destas crianças e jovens e como devem se portar em diferentes espaços, seja em casa, na fazenda ou no colégio. Passemos, pois às obras e algumas ilustrações de cada uma delas.

\section{Livros e imagens}

Les vancances é um dos títulos que fazia parte da Bibliothèque rose da editora Hachette que era vendida em quiosques das estações de trem francesas. Les vacances tinha 345 páginas e 40

\footnotetext{
${ }^{1}$ Doutoranda da Faculdade de Educação da Unicamp, Campinas, São Paulo, Brasil. E-mail: prikco@gmail.com.

${ }^{2}$ As férias.

${ }^{3}$ Mulherzinhas.
} 
ilustrações. O ilustrador era Bertall o pseudônimo de Albert Amoux, que se formou em desenho trabalhando no atelier de Drolling. Fez ilustrações para várias editoras, entre elas, a Hachette.

No livro há e reunião de uma mãe viúva, suas duas filhas, outra mãe que supostamente era viúva, com sua filha e uma menina que é acolhida por essa família. No início do livro as quatro meninas querem arrumar os quartos com flores em vasos para receber os três primos e seus pais.

$\mathrm{Na}$ imagem abaixo vemos quatro meninas carregando flores em cestas, vasos e um carrinho de mão com flores. Elas têm atrás um jardim repleto de flores e arbustos, típicos das mansões aristocráticas da França. As meninas possuem vestidos de manga curta e saias rodadas, usando sapatos e com os cabelos bem presos em tranças. Trata-se de um meio aristocrático, que é difundido pelas imagens e pela narrativa do livro. As meninas precisam ser bondosas, gentis e saber conversar com os primos e demais adultos e estão contentes em receber os familiares.

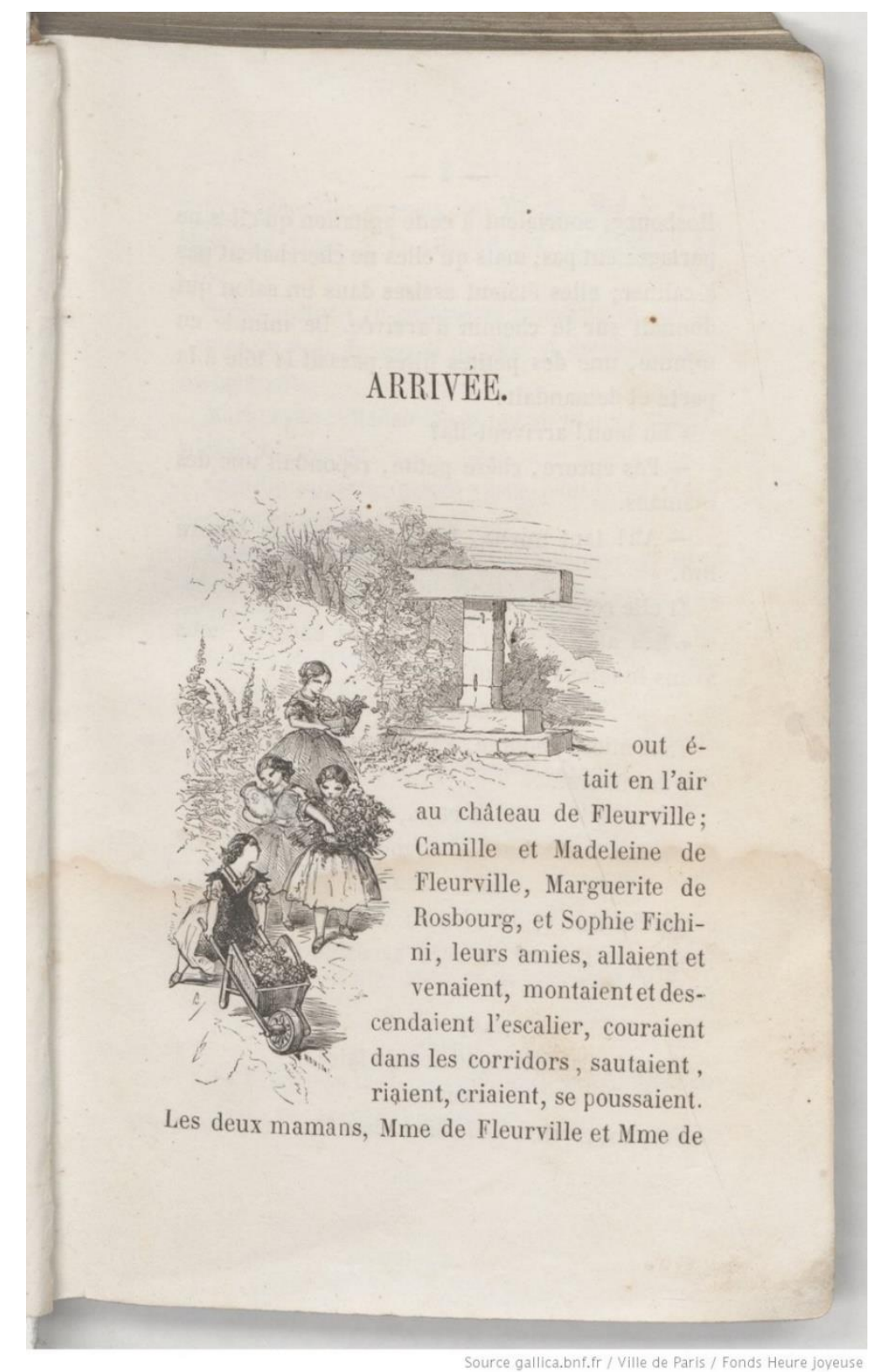

Condessa de Ségur, Les vacances, p. 3, 1861, por Bertall. 
Little women, por sua vez, apresenta uma família, de característica mais próxima da organização burguesa, composta por quatro irmãs, sua mãe e sua babá. O pai está distante, como capelão da Guerra Civil, retornando ao final da primeira parte do livro.

A primeira edição foi publicada com o título Little women or Meg, Jo, Beth and Amy pela editora Roberts Brothers. Foram impressos dois mil livros dessa primeira versão, que tinha encadernação de capa dura revestida com tecidos nas cores verde, roxa e terracota. O livro possui 341 páginas e com quatro ilustrações de May Alcott, irmã de Louisa May Alcott. Ela gostava de pintar e até estudou por algum tempo em Paris e ganhou um prêmio por fazer cópias de William Turner.

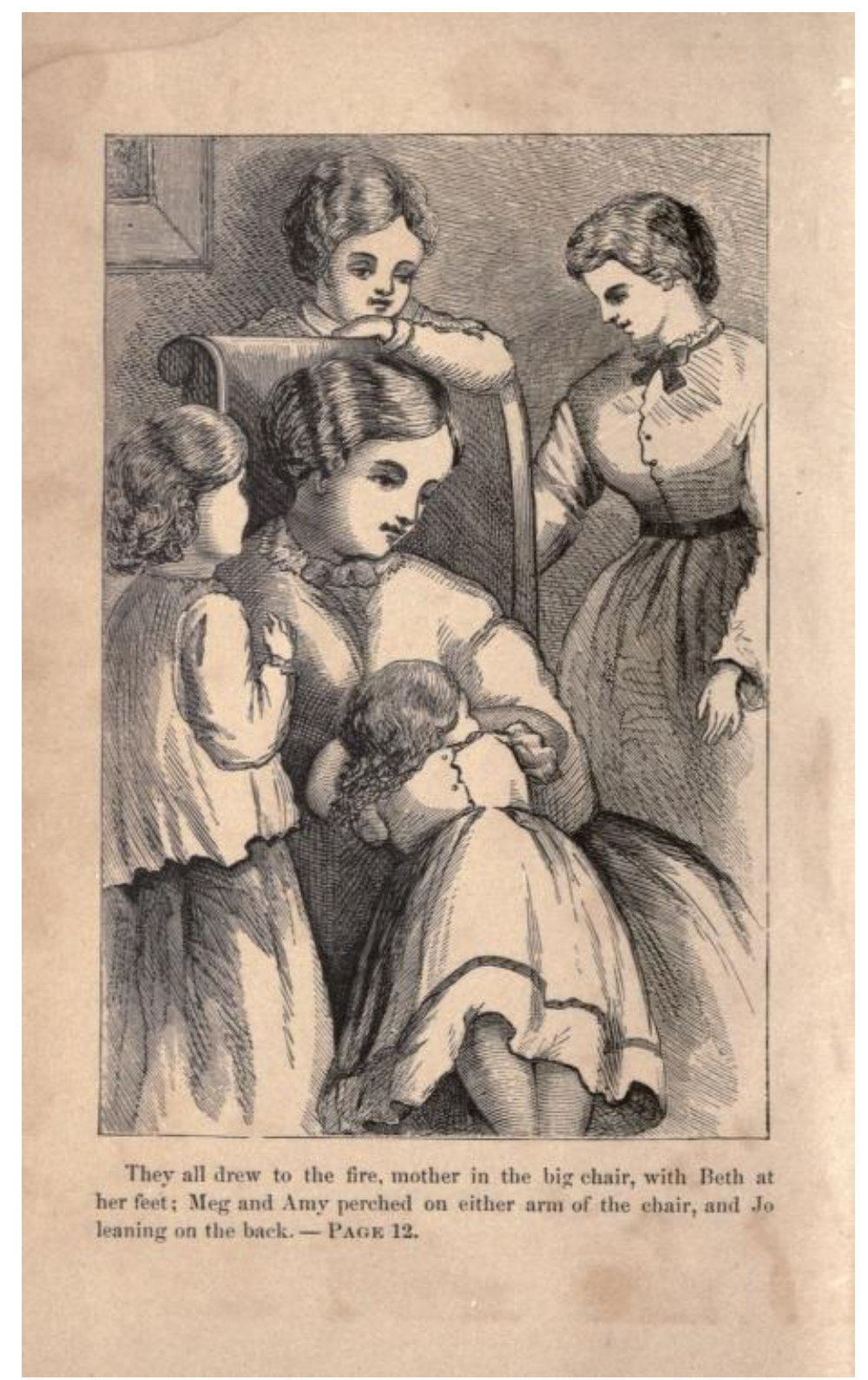

Louisa May Alcott, Little women, 1868, p. 05, de May Alcott.

A ilustração deste livro traz a mãe sentada em uma poltrona, uma das marcas de uma casa burguesa. A mãe possui um cabelo arrumado, bem como as filhas, que possuem vestidos longos e saias rodadas, com laços e botões. Apenas a criança mais nova possui um vestido mais curto. 
Atrás da poltrona a um quadro, um resquício da vida uma passagem da aristocracia para a vida burguesa, que aprende a consumir arte. As jovens rodeiam a mãe, com ar carinhoso, gostando de ficar próxima da matriarca.

Já em Clarita no colégio, Maria Clarice Marinho Villac apresenta uma família mais próxima da organização patriarcal com os avós maternos, os pais, tios e muitos empregados. Estes últimos constituem parte da família, pois estão presentes nas atividades dos demais membros e interferem em seus afazeres e são filhos de pais que foram escravizados. Eles vivem nas fazendas, eventualmente com algum salário. No colégio também há empregadas negras, que realizam os trabalhos domésticos, como a alimentação, a lavagem de roupas e limpeza.

O livro Clarita no colégio foi impresso pela editora Cristo-Rei com 210 páginas e 17 imagens. O ilustrador Manuel Romano, conhecido como o caricaturista Manolo, que nasceu em Campinas (SP) e trabalhou em diferentes periódicos. Ele foi contratado por Maria Clarice, que mostrou fotografias para que fizesse as imagens.

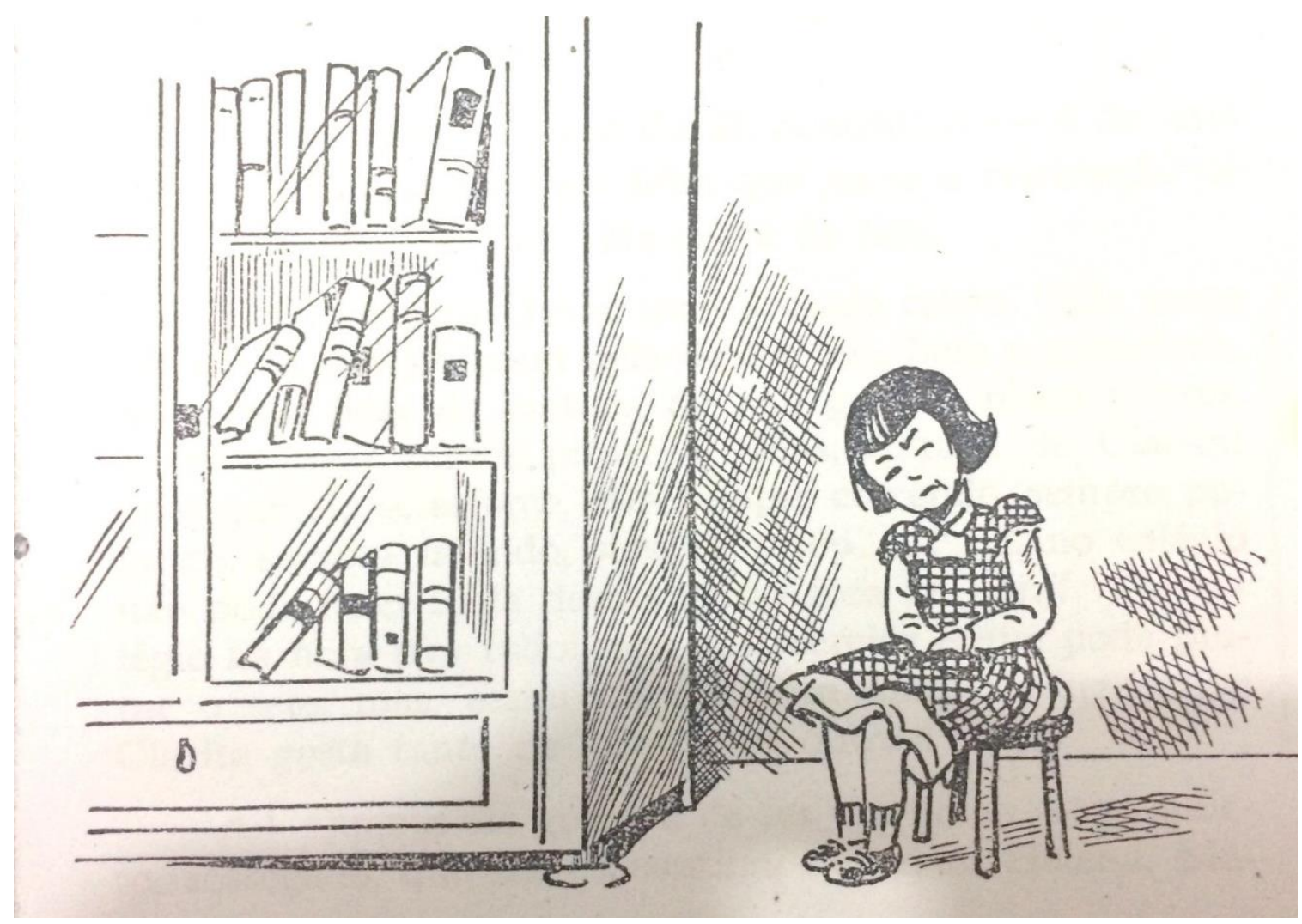

Maria Clarice Marinho Villac, Clárita no colégio 1945, p. 05, de Manolo.

Na ilustração há a criança sentada no escritório da diretora, para refletir sobre sua conduta de correr no pátio. Ao lado do banquinho há um armário repleto de livros e com portas de vidro, que protegem objetos que trazem o conhecimento. Clarita está sentada com um vestido de saia rodada e com sapatos e meias. Seu cabelo é curto e seu olhar é de insatisfação.

Cada imagem traz um pouco do comportamento destas meninas e jovens, com olhares e maneiras de estar. Meninas exemplares caminham com alegria ou têm um olhar amoroso para a mãe ou podem ter um ar desgostoso por ter de sentar num banquinho no escritório da diretora. Essas ilustrações, que caminham lado a lado com a história dos livros, permitem identificar como a representação de meninas e jovens foram sendo construídas ao longo do tempo e como 
permanecem em nossos dias, uma vez que os livros continuam sendo produzidos, inclusive sendo traduzidos para vários países no mundo.

\section{Considerações finais}

As representações das meninas e jovens trazem, por meio das ilustrações, apresenta os espaços e vestimentas femininas existentes naquele tempo. São crianças de uma elite aristocrática, burguesa e patriarcal cuja expectativa era de uma determinada maneira de se vestir e se comportar. Se as meninas e jovens eram travessas e rebeldes, adultos precisavam indicar a maneira mais adequada. Os corpos precisam ser disciplinados para que sejam apropriadas a cada situação e lugar. As imagens, que caminham em consonância com as histórias, trazem o que é esperado para essas personagens e também para seus leitores.

É preciso atentar que tais expectativas já não podem ser as mesmas na contemporaneidade. Novos olhares devem ser lançados e perceber em que medida tais representações devem ser alteradas ou rejeitadas.

\section{Referências}

ALCOTT, Louisa May. Little women: or Meg, Jo, Beth and Amy. Boston (EUA): Roberts Brothers, 1880, Disponível em: <https://archive.org/details/littlewomenormeg00alcoiala>. Acessado em: 12 de dezembro de 2015.

CHARTIER, Roger. Mundo como representação. Estudos Avançados, São Paulo, Instituto de Estudos Avançados da Universidade de São Paulo, v. 5, n. 11, jan./abr. 1991, p. 173-191.

COMTESSE DE SÉGUR. Les vacances. Paris: Hachette, 1861. Disponível em: 〈http://gallica.bnf.fr/ark:/12148/bpt6k6577519b/f7.image>. Acessado em: 25 de novembro de 2015.

PERROT, Michelle (Org.). História da vida privada: da Revolução Francesa à Primeira Guerra. São Paulo (SP): Companhia das Letras, 2009.

VIOLETA MARIA. (Maria Clarice Marinho Villac). Clarita no Colégio. São Paulo: CristoRei, 1945. 